\title{
Recursive Thick Modeling and the Choice of Monetary Policy in Mexico
}

(Preliminary and Incomplete: May 2006)

\author{
Arnulfo Rodriguez ${ }^{*}$
}

Pedro N. Rodriguez ${ }^{* *}$

\footnotetext{
* Dirección General de Investigación Económica, Banco de México. I thank Alberto Torres, Jéssica Roldán and Julio Pierre-Audain for familiarizing me with analytical and computational tools of key importance to this research work. I also thank Pedro León de la Barra and Mario Oliva for excellent research assistance. The opinions in this paper correspond to the authors and do not necessarily reflect the point of view of Banco de México.

** Departamento de Estadística e Investigación Operativa II, Universidad Complutense de Madrid.
} 


\title{
Recursive Thick Modeling and the Choice of Monetary Policy in Mexico
}

\author{
(Preliminary and Incomplete: May 2006)
}

Arnulfo Rodriguez

Pedro N. Rodriguez

\begin{abstract}
By following the spirit in Favero and Milani (2005), we use recursive thick modeling to take into account model uncertainty for the choice of optimal monetary policy. We consider an open economy model and generate multiple models for only the aggregate demand and aggregate supply. We use a rolling window of fixed size for the estimations. The Schwarz's Bayesian Information Criterion (BIC) and the adjusted $\mathrm{R}^{2}$ are the two statistical criteria selection methods used to rank all of the generated output gap and core inflation models. Models are constructed by matching the rankings of aggregate demand and aggregate supply and adding other specifications for the rest of the variables. The weights are based on BIC and $\overline{\mathrm{R}}^{2}$ in sample criteria. The main results show that recursive thick modeling with equal weights approximates the recent historical behavior of nominal interest rates in Mexico better than a weighted average based on any criterion. Furthermore, recursive thick modeling with simple and weighted averages works better than recursive thin modeling.
\end{abstract}

JEL Classification: C61, E61

Keywords: macroeconomic policy, model uncertainty, optimal control, monetary policy, inflation targeting. 


\section{INTRODUCTION}

An approach for dealing with parameter instability and non-linearity is proposed by Pesaran and Timmermann (1995) in the context of small models. They address those potential problems by using recursive modeling. Favero and Milani (2005) not only do they use the same approach in the analysis of optimal monetary policy for the US economy, but they also complement it with the thick modeling approach proposed by Granger and Jeon (2004). Favero and Milani (2005) generate $2^{\mathrm{k}}$ models in every period by making all of the possible combinations from a set of $k$ regressors. This way of combining regressors allows them to take into account the uncertainty in the number of lags with which the relevant variables enter into both the aggregate demand and aggregate supply specifications. Here we also do the same to the analysis of optimal monetary policy in Mexico in order to assess the relevance of model uncertainty.

Unlike Favero and Milani (2005), we consider an open economy model. The $2^{\mathrm{k}}$ models are only generated for the output gap and core inflation. We use a rolling window of fixed size for the estimations. The Schwarz's Bayesian Information Criterion (BIC) and the adjusted $\mathrm{R}^{2}$ are the two statistical criteria selection methods used to rank all of the generated output gap and core inflation models. However, the results show that the rankings given by one criterion do not necessarily correspond to the rankings obtained from the other. The output gap and core inflation models are grouped together according to their ranking - i.e. the best output gap model with the best core inflation model, the second best output gap model with the second best core inflation model, etc. We obtain the optimal policies derived from all of the relevant models. ${ }^{1}$

The lack of correspondence between the rankings given by the statistical criteria makes the decision to exclusively rely on the best model in every period somewhat difficult. By considering the rest of the models we take into account model uncertainty for

\footnotetext{
${ }^{1}$ Models in which monetary policy does not play a role in controlling core inflation through the demand channel are not considered.
} 
determining optimal monetary policy. It is worth mentioning that the resulting thick line reflects the degree of model uncertainty derived only from the dynamic structure of the economy - i.e. which relevant lags to consider for some variables. Other types of uncertainty as defined by Jenkins and Longworth (2002) and related to additive shocks, duration of shocks and data are not addressed in this paper. Neither do we directly incorporate parameter uncertainty à la Brainard (1967) to determine its effect on optimal policy. Söderström (2002) studies the effect of uncertainty in the inflation persistence parameter on optimal policy. The other approach to deal with model uncertainty is robust control as in Hansen and Sargent (2003) and Onatski and Stock (2002).

The implied optimal nominal interest rates for any given period substantially vary across specifications. Moreover, we are able to do a better tracking job of the actual nominal interest rates when we obtain the simple and weighted averages for the optimal nominal interest rates. These results argue in favor of making it necessary to take model uncertainty into account when setting monetary policy.

By statistically comparing the MSEs obtained from the average optimal policies given by different preference parameters, we are able to reveal only a range in which the revealed preference parameters could be. ${ }^{2}$ We do the same statistical comparison between simple and weighted averages only for the preference parameters $\alpha=0.5, \phi=0.3$. We find that simple averages work better than weighted averages. The results also show both reductions in bias and standard deviation in tracking the actual nominal interest rates when using either simple or weighted averages of optimal nominal interest rates.

The results also indicate that the set of variables belonging to the best specification for both the output gap and core inflation is changing through time.

In this paper we take the uncertainty analysis done by Favero and Milani (2005). Our basic model is a modified version of the dynamic aggregate supply-aggregate demand

\footnotetext{
${ }^{2}$ We cannot exactly reveal the true preference parameters since our analysis only considers six cases. A finer grid search would get us very close to the true preference parameters. See Roldán-Peña (2005) for revealing preference parameters with finer grids.
} 
framework used by Rudebusch and Svensson (1999). The original framework was modified to include open economy variables. The dynamic homogeneity condition is imposed on the Phillips curve for core inflation, which is similar to the one used by Contreras and García (2002). ${ }^{3}$ The IS curve is similar to the one used by Ball (1999). The equations used are:

$\pi_{t}^{c}=\beta_{1} \pi_{t-1}^{c}+\beta_{2} X_{t-2}+\left(1-\beta_{1}\right) d e \inf e u_{t}+\varepsilon_{t}^{\pi}$

$x_{t}=\gamma_{0}+\gamma_{1} x_{t-1}+\gamma_{2} x_{t-1}^{u s}+\gamma_{3} l t c r_{t}+\gamma_{4} r_{t-1}+\varepsilon_{t}^{x}$

Equation (1) is an open economy Phillips curve where core inflation $\pi_{t}^{c}$ is affected by its own lag $\pi_{t-1}^{c}$, the output gap second lag $x_{t-2}$, and the sum of the contemporaneous nominal exchange rate percentage depreciation and the external inflation deinf $e u_{t}$. We impose the dynamic homogeneity condition in equation (1) to guarantee long run inflation neutrality on output. ${ }^{4}$

Equation (2) is an open economy IS equation where the output gap $x_{t}$ is affected by its own lag $x_{t-1}$, the lag of the US output gap $x_{t-1}^{u s}$, the lag of the ex-post real interest rate $r_{t-1}$ and the contemporaneous value of the natural log of the real exchange rate $\operatorname{ltcr}_{t} \cdot \varepsilon_{t}^{\pi}$ and $\varepsilon_{t}^{x}$ are the respective white noise shocks. We use monthly data for core inflation, output gap, the real exchange rate and the ex-post real interest rate.

Under the restrictions given by equations 1-2 along with other specifications for exogenous variables, the central bank minimizes an intertemporal loss function by optimally setting the nominal interest rate. Initially, it is assumed that this single model

\footnotetext{
${ }^{3}$ As opposed to the Phillips curve used by those authors, ours does not have a forward-looking inflation component. The reasons for not having included forward-looking variables will be given in the next sections. ${ }^{4}$ Data was obtained from Banco de México. The output gaps are percentage deviations of the seasonal adjusted Index of General Economic Activity (IGAE) and the seasonal adjusted US Industrial Production Index from their respective output potential. The output potentials represent an average of a linear trend and a Hodrick-Prescott filter. The log of the real exchange rate is the natural logarithm of the US-Mexico real exchange rate index $(1997=1.0)$. The monthly nominal interest rate was obtained from the 28-day Mexican government T-bill (CETES).
} 
contains the correct representation of the economy and that the model parameters are constant over time.

\section{PARAMETER INSTABILITY}

Using monthly data over the period 1996:09-2004:06, the estimated equations are as follows ${ }^{5}$ :

$$
\begin{aligned}
& \pi_{t}^{c}=\underset{(0.0000)}{0.980553 \pi_{t-1}^{c}-\underset{(0.8593)}{0.001480 x_{t-2}}+0.019446 \text { de inf } e u_{t}+\varepsilon_{t}^{\pi}} \\
& x_{t}=\underset{(0.1773)}{0.221060}+0.528036 x_{t-1}+0.336692 x_{t-1}^{u s}+0.042619 \text { ltcr }_{t}-0.036376 r_{t-1}+\varepsilon_{t}^{X}
\end{aligned}
$$

To evaluate the potential parameter instability we re-estimate each equation by considering two different sub-samples. For the core inflation equation, the sub-samples estimation yields:

$$
\begin{array}{ccc}
\text { 1996:10 - 1999:05 } & \pi_{t}^{c}=\underset{(0.0000)}{0.950851} \pi_{t-1}^{c}-\underset{(0.9394)}{0.002188 x_{t-2}}+0.049148 d e \inf e u_{t}+\varepsilon_{t}^{\pi} \\
\text { 1999:06 - 2004:06 } & \pi_{t}^{c}=\underset{(0.0000)}{1.008711} \pi_{t-1}^{c}-\underset{(0.2092)}{0.006685 x_{t-2}}-0.008710 d e \inf e u_{t}+\varepsilon_{t}^{\pi}
\end{array}
$$

For the output gap equation, the sub-samples estimation yields:

1996:09 - 1999:12

$$
x_{t}=0.301036+0.588008 x_{t-1}+0.069202 x_{t-1}^{u s}-2.893024 l t c r_{t}-0.030888 r_{t-1}+\varepsilon_{t}^{X}
$$

2000:01 - 2004:06

$$
x_{t}=-0.752512+0.115780 x_{t-1}+0.620912 x_{t-1}^{u s}-4.185126 \text { ltcr }_{t}+0.007044 r_{t-1}+\varepsilon_{t}^{X}(8)
$$

\footnotetext{
${ }^{5}$ Values in parenthesis are p-values.
} 
We take these results as an indication of parameter instability of economic relevance. Performing a Chow test of the null of parameter stability on the output gap equation, we find a potential breakpoint at date 2000:01 and reject the hypothesis of no breakpoint at the 5\% significance level. Doing the same for the core inflation equation we find a potential breakpoint at date 1999:06. However, since the variances of the residuals for each of the sub-samples are significantly different, a Chow test is no longer satisfactory, so we perform a Wald test, as suggested by Watt (1979) and Honda (1982), which provides conclusive evidence against the stability of core inflation: we reject the hypothesis of equal parameters at the $5 \%$ significance level.

Favero and Milani (2005) explain that recursive modeling consists of updating the economic model by choosing the best possible representation of the unknown Data Generating Process over a base set of $k$ regressors. They also take into account the models not chosen in order to consider specification uncertainty.

Estimations are obtained by using a rolling window of fixed length and take into account the dynamic homogeneity property as well as some parameters restrictions which reflect some assumptions about long-term values for the real interest rate and the real exchange rate. The window size does not come from an optimization procedure and is set equal to fifty two observations. We use monthly data from September 1996 to May 2004. The first period estimations are obtained with data from September 1996 to December 2000. When using the rolling window of fixed length, we obtain all the optimal nominal interest rates implied by each model for the forty two periods starting in January 2001 and ending in June 2004. These implied optimal nominal interest rates represent one-step ahead forecasts since we are mimicking a policy maker who optimizes a loss function subject to specifications estimated with all the available data up to that point.

We assume no uncertainty for the real exchange rate equation and the rest of the equations for the exogenous variables. The technical complications of allowing a forwardlooking component in the real exchange rate equation makes it very difficult to consider 
uncertainty on this particular specification. ${ }^{6}$ In other words, estimating models derived from all the possible combinations of $k$ regressors could be unwieldy when using GMM for specifications with forward-looking variables.

Recursive modeling is implemented by considering the following specifications:

$$
\begin{aligned}
& M_{i, t}^{A S}: \pi_{t}^{c}=\beta_{1} \pi_{t-1}^{c}+\beta_{i}^{\prime} \mathbf{X}_{t, i}^{1}+u_{t, i}^{1}, \\
& M_{i, t}^{A D}: x_{t}=\gamma_{0}+\gamma_{1} x_{t-1}+\gamma_{i}^{\prime} \mathbf{X}_{t, i}^{2}+u_{t, i}^{2},
\end{aligned}
$$

where $\mathbf{X}_{t, i}^{1}, \mathbf{X}_{t, i}^{2}$ are $\left(k_{i} \times 1\right)$ vectors of regressors under models $M_{i, t}^{A S}, M_{i, t}^{A D}$, obtained as a subset of the base set of regressors $\mathbf{X}_{t}^{1}, \mathbf{X}_{t}^{2}$

$$
\begin{aligned}
& \mathbf{X}_{t}^{1^{\prime}}=\left[\begin{array}{llllllllll}
\pi_{t-2}^{c} & \pi_{t-3}^{c} & x_{t} & x_{t-1} & x_{t-2} & x_{t-3} & \text { deinfeu } & \text { deinfeu } \\
t-1 & \text { deinfeu }_{t-2} & \text { deinfeu } \\
t-3
\end{array}\right] \\
& \mathbf{X}_{t}^{2^{\prime}}=\left[\begin{array}{lllllllllll}
x_{t-2} & x_{t-3} & x_{t-1}^{u s} & x_{t-2}^{u s} & \operatorname{ltcr}_{t} & \operatorname{ltcr}_{t-1} & r_{t-1} & r_{t-2} & r_{t-3} & r_{t-4}
\end{array}\right]
\end{aligned}
$$

where $k_{i}=\mathbf{e}^{\prime} u_{i}$, $\mathbf{e}$ is a $(k \times 1)$ vector of ones, and $\mathbf{u}_{i}$ is a $(k \times 1)$ selection vector composed of zeros and ones, where a one in its j-th element means that the $\mathrm{j}$-th regressor is included in the model. All variables are defined as above and $r_{t}=i_{t}-12 \pi_{t}$. The first lag of each dependent variable is always included in all specifications. Uncertainty on the specification of lags implies that the policy maker searches over $2^{10}=1024$ specifications to select in each period the relevant demand and supply equations. The selection criterion is either based on adjusted $\mathrm{R}^{2}$ or Schwarz's Bayesian Information Criterion (BIC). The formula for the latter is obtained from Bossaerts and Hillion (1999).

The rest of the specifications for other variables is obtained from Roldán-Peña (2005) and given by the following:

$$
\text { Itcr } r_{t}=\alpha_{1}\left(l t c r_{t-1}\right)+\alpha_{2}\left(\operatorname{ltcr}_{t+1}^{e}+\frac{\left(r_{t}^{u s}-r_{t}\right)}{1200}\right)+v_{t}
$$

\footnotetext{
${ }^{6}$ We decided to use an interest parity condition with delayed overshooting for the real exchange rate similar to the one in Eichenbaum and Evans (1995) and Gourinchas and Tornell (1996).
} 


$$
\begin{aligned}
& \pi_{t}^{n c}=d_{0}+d_{1} \pi_{t-1}^{n c}+w_{t} \\
& \pi_{t}=\lambda \pi_{t}^{c}+(1-\lambda) \pi_{t}^{n c} \\
& d e_{t}+\pi_{t}^{u s}=d t c r_{t}+\pi_{t}
\end{aligned}
$$

and the VAR(2) system for the exogenous external variables::

$$
\begin{aligned}
& \pi_{t}^{u s}=a_{0}+a_{1} \pi_{t-1}^{u s}+a_{2} \pi_{t-2}^{u s}+a_{3} x_{t-1}^{u s}+a_{4} x_{t-2}^{u s}+a_{5} i_{t-1}^{u s}+a_{6} i_{t-2}^{u s}+\vartheta_{t} \\
& x_{t}^{u s}=b_{0}+b_{1} \pi_{t-1}^{u s}+b_{2} \pi_{t-2}^{u s}+b_{3} x_{t-1}^{u s}+b_{4} x_{t-2}^{u s}+b_{5} i_{t-1}^{u s}+b_{6} i_{t-2}^{u s}+s_{t} \\
& i_{t}^{u s}=c_{0}+c_{1} \pi_{t-1}^{u s}+c_{2} \pi_{t-2}^{u s}+c_{3} x_{t-1}^{u s}+c_{4} x_{t-2}^{u s}+c_{5} i_{t-1}^{u s}+c_{6} i_{t-2}^{u s}+z_{t}
\end{aligned}
$$

Equations 11-13 represent the dynamic specifications for the real exchange rate, non-core monthly inflation, monthly headline inflation as a weighted sum of its core and non-core components and the purchasing power parity condition, respectively. The VAR(2) system represents the dynamics for the US monthly headline inflation, US output gap and US nominal interest rates obtained from the 3 month T-bill. See Roldán-Peña (2005) for estimation of equations 11-16.

We take into consideration only 960 models from all the possible combinations of 10 regressors for both the aggregate supply and aggregate demand equations. This is the case since the $2^{6}$ models resulting from not having the variables $r_{t-1}, r_{t-2}, r_{t-3}$ and $r_{t-4}$ are discarded as possible specifications for the output gap. Similarly, the $2^{6}$ models resulting from not having the variables $x_{t}, x_{t-1}, x_{t-2}$ and $x_{t-3}$ are eliminated from the set of possible specifications for core inflation. This is done in order to take into account only models that make monetary policy relevant to control inflation.

Finally, we combine the output gap and core inflation specifications according to their rankings given by either BIC or adjusted $\mathrm{R}^{2}$ - i.e. the best output gap specification with the best core inflation specification, the second best output gap specification with the second best core inflation specification, etc. Even though the uncertainty considered here relates only to the dynamic structure of the economy (thus omitting other factors that may influence uncertainty), the advantage of this approach is that it allows us to account for the number of lags with which monetary policy affects the economy. 
Having estimated all possible models, a statistical criterion is used to select a single model to design optimal policy for each period (recursive thin modeling). Alternatively, the information from the whole set of models can be used in each period (recursive thick modeling).

Thin modeling discards all but one model for each dependent variable, leaving out of the decision-making process the information from $\left(2^{k}-1\right) * 2$ models - i.e. since the uncertainty about the number of lags only applies to the aggregate demand and aggregate supply specifications. Although the chosen model is the best according to some criterion, exclusively relying on it means that the policy maker does not consider the uncertainty stemming from both unstable parameters and model specification.

One problem about thin modeling pointed out by Favero and Milani (2005) has to do with the lack of match between the ranking of models obtained from different statistical criteria. Figures 1 and 2 show scatter plots of models ranking according to adjusted $\mathrm{R}^{2}$ and BIC criteria for all the 960 specifications of aggregate supply and aggregate demand, respectively. 


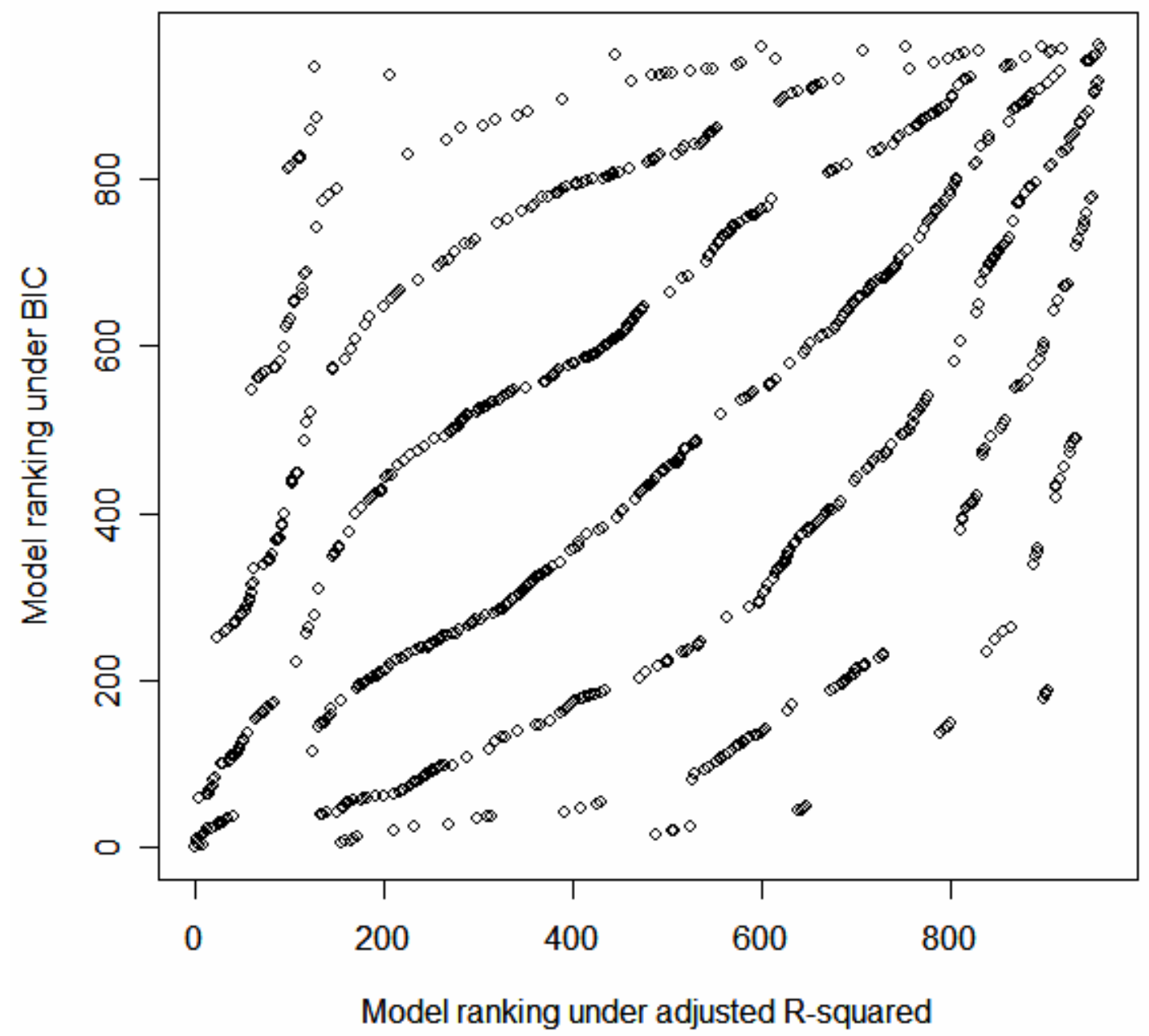

Figure 1. Scatter plot of models ranking under BIC and adjusted $\mathrm{R}^{2}$ for all the 960 possible specifications of core inflation for the last period. 


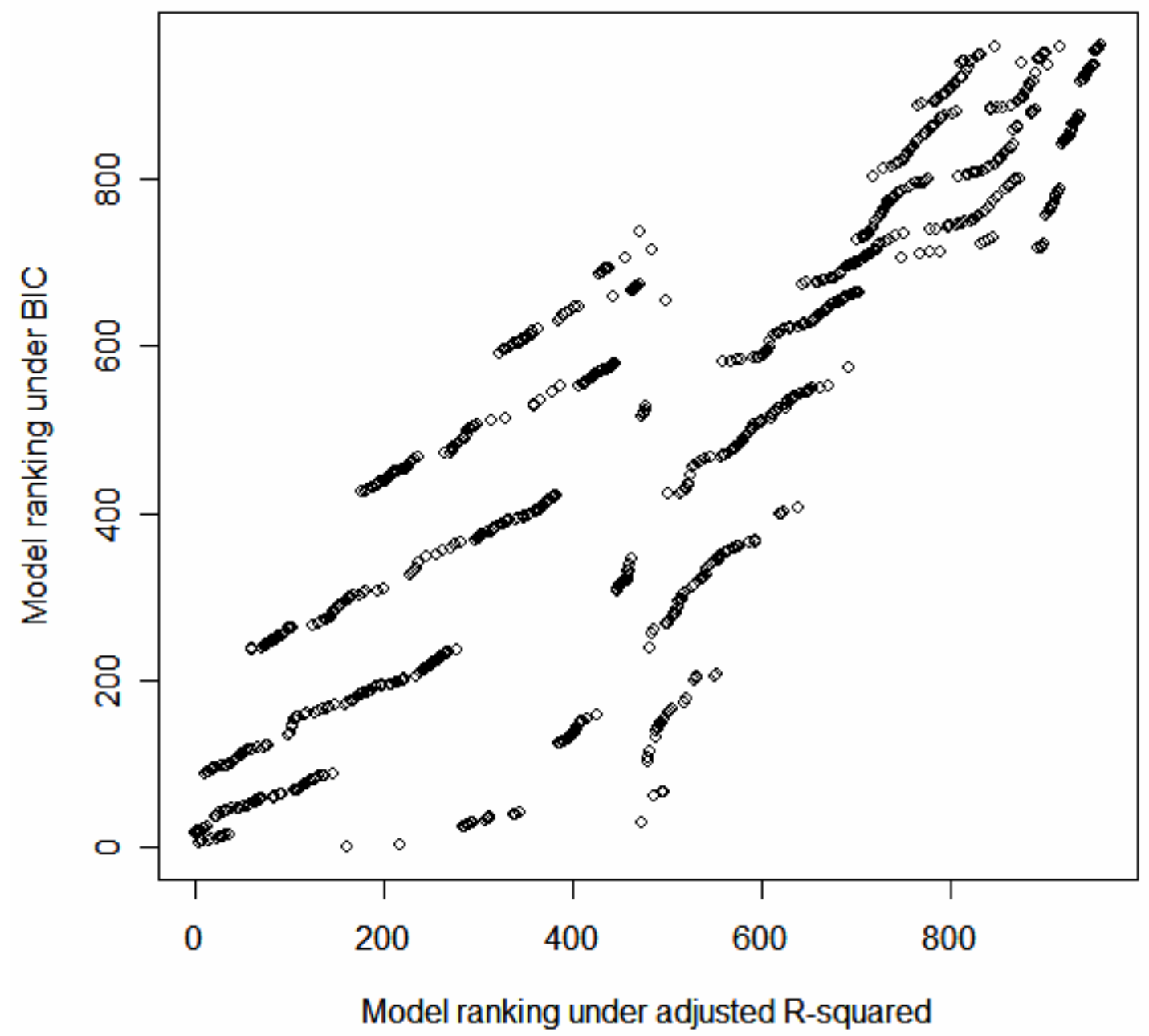

Figure 2. Scatter plot of models ranking under BIC and adjusted $\mathrm{R}^{2}$ for all the 960 possible specifications of the output gap for the last period.

As it can be seen from those figures, the lack of match between the ranking of models also arises. For instance, the best output gap model according to adjusted $\mathrm{R}^{2}$ (BIC) is ranked in the $17^{\text {th }}\left(162^{\text {th }}\right)$ place by the BIC (adjusted $R^{2}$ ) criterion. As for the core inflation, the best model according to adjusted $\mathrm{R}^{2}$ coincides with the best one ranked by the BIC criterion. However, any given selection criterion is prone to producing small, statistically insignificant differences among the best models. Dell'Aquila and Ronchetti 
(2004) find out that ranking is unreliable in the sense that the set of undistinguishable models can be large.

Consequently, deciding which model to choose becomes hard. One way to evaluate the importance of this choice consists of finding how robust the key parameters are across both time and the 960 specifications. Figures 3,4 and 5 show the variation of the long run coefficients for the real interest rate, the US output gap and the imported inflation across both time and specifications. ${ }^{7}$ The dotted yellow line and the solid blue line placed on the red area indicate the average of the long-run coefficients across the 960 models and the long-run coefficient given by the best model, respectively.
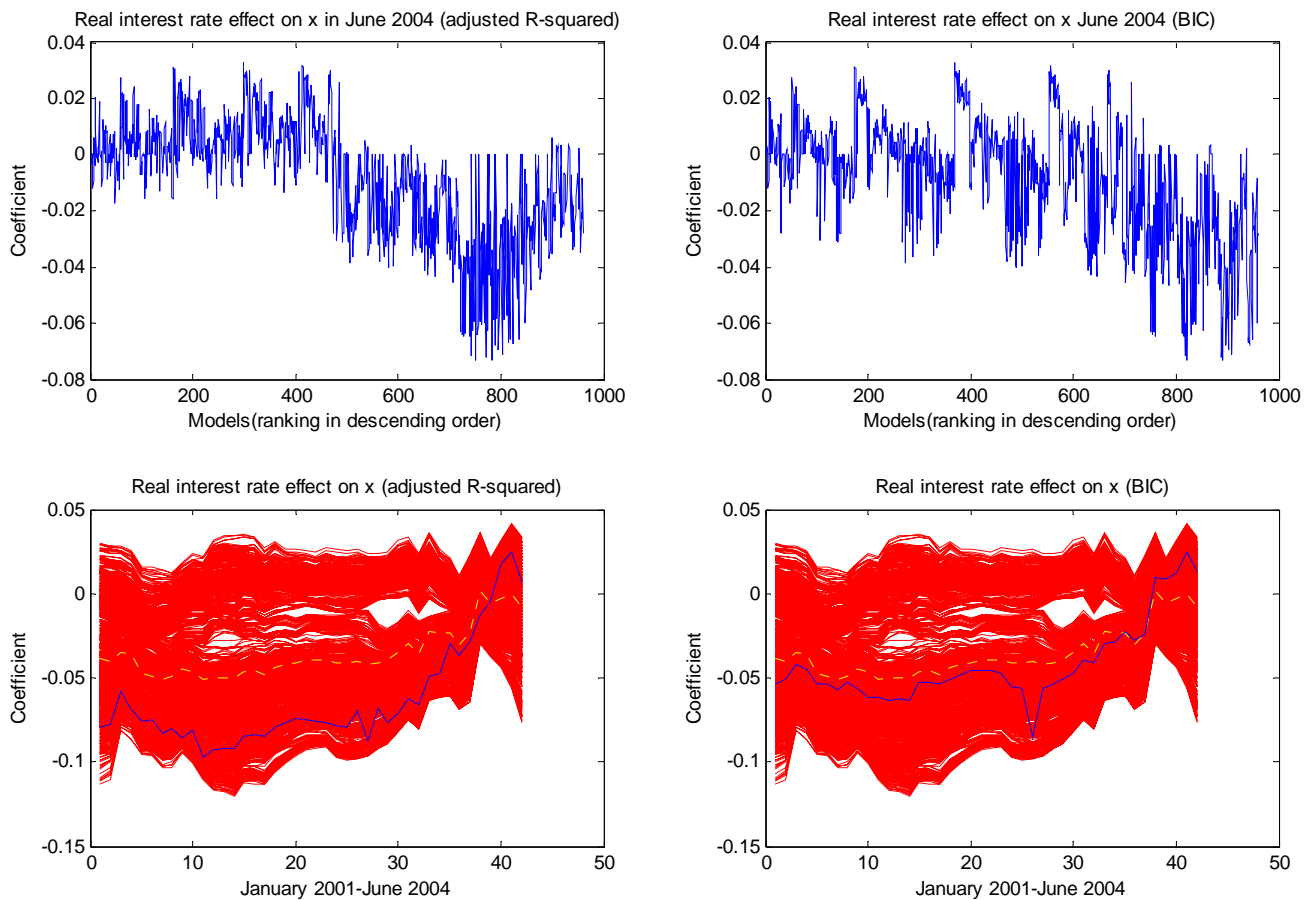

Figure 3. Variation of the real interest rate coefficient across specifications and time.

\footnotetext{
${ }^{7}$ Long run coefficients are obtained by adding all the coefficients of the corresponding variable for each specification.
} 

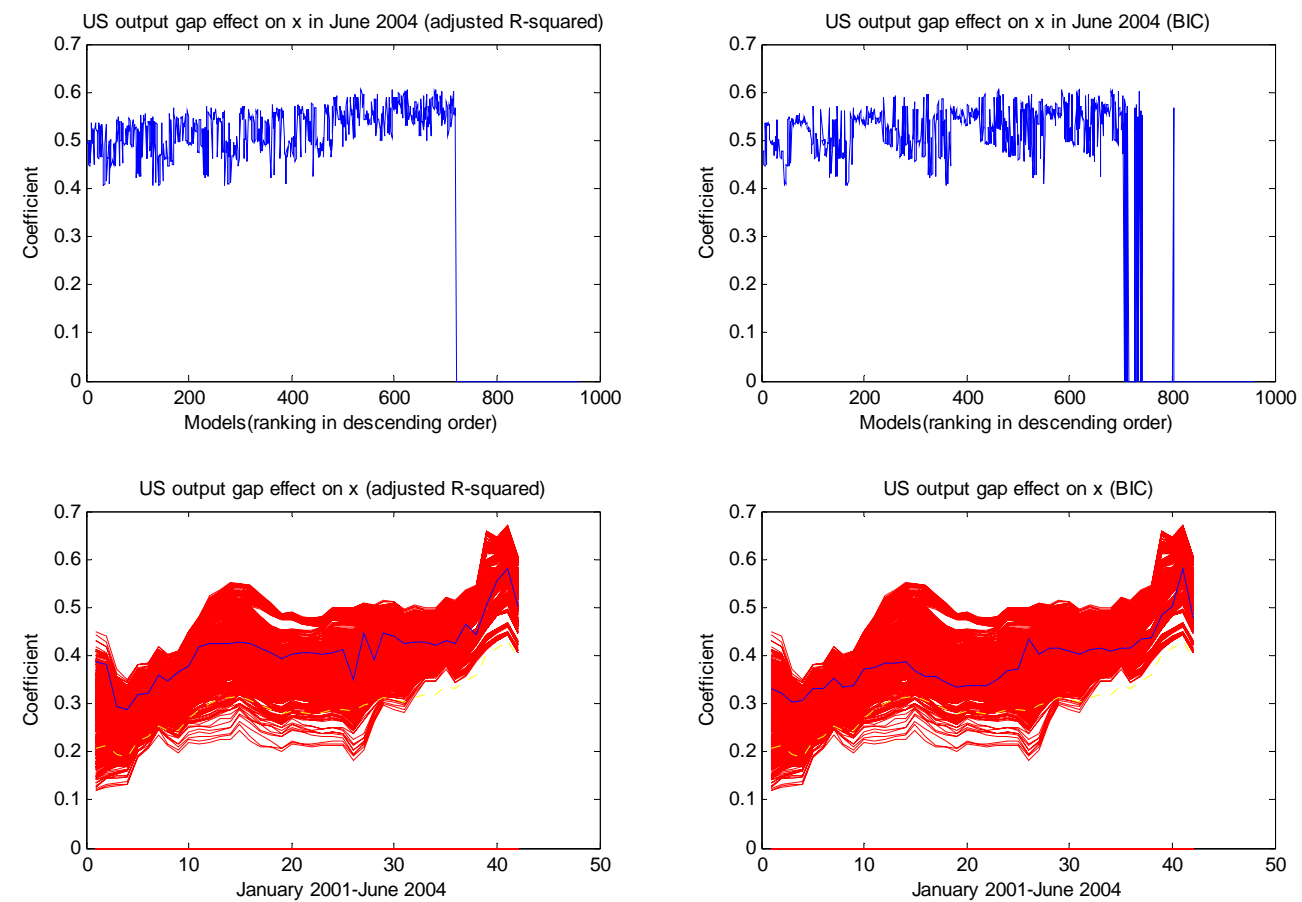

Figure 4. Variation of the US output gap coefficient across specifications and time.
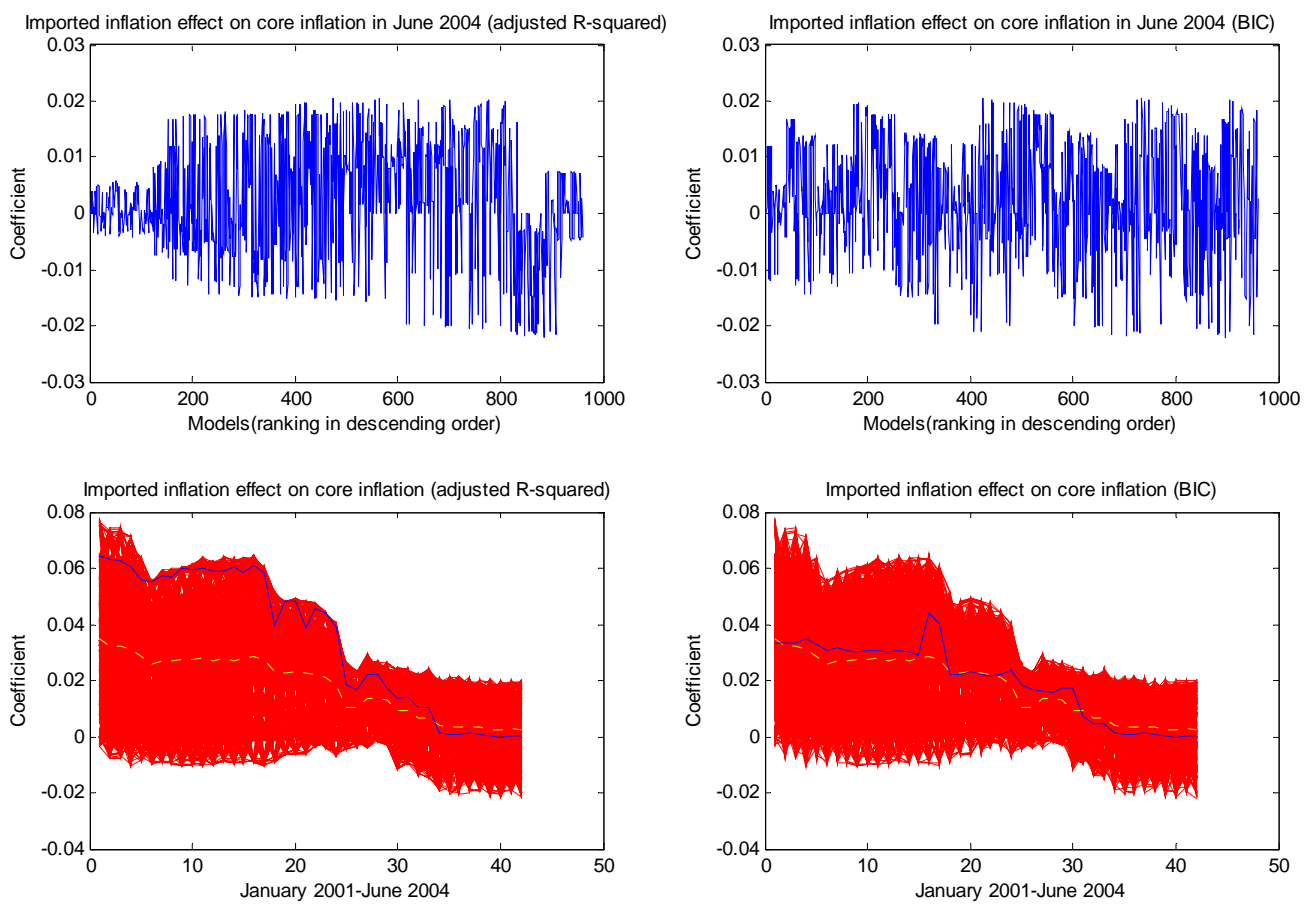

Figure 5. Variation of the imported inflation coefficient across specifications and time. 
In the next section we will find out how relevant the range for those coefficients is to optimal policy.

\section{OPTIMAL MONETARY POLICY}

To asses the impact of recursive thick modeling, we calculate the optimal nominal interest rate paths based on the following model choices:

- $\quad$ Recursive thin modeling: the model with the best adjusted $\mathrm{R}^{2}$.

- Recursive thin modeling: the model with the best BIC.

- Recursive thick modeling: the average (simple or weighted) optimal monetary policy derived from all specifications for each statistical criteria.

The policy maker minimizes an intertemporal loss function of the form:

$$
L_{t}=E_{t}\left\{\sum_{i=0}^{\infty} \beta^{i}\left[(1-\phi)\left[144 \alpha\left(\pi_{t+i}-\pi^{*}\right)^{2}+(1-\alpha) y_{t+i}^{2}\right]+\phi\left(i_{t+i}-i_{t-1+i}\right)^{2}\right] \mid \mathrm{M}\right\}
$$

The period loss function is quadratic in the deviations of output and inflation from their targets, and it includes a penalty for the policy instrument's variability. The policy maker's preference parameter $\alpha$ represents the relative weight of inflation stabilization to output gap stabilization (which gives a sum of 1). Additionally, the other policy maker's preference parameter $\phi$ symbolizes the relative weight of interest rate smoothing to stabilization of inflation and output (again adding up to 1). The policy maker's minimization problem is conditional to the set of $2^{\mathrm{k}}$ specifications $\mathrm{M}$.

We proceed to solve the optimization problem under different assumptions regarding the policy maker's preferences in order to evaluate which weighting scheme delivers the best performance in replicating the actual nominal interest rate. We calculate the optimal monetary policy rules implied by recursive thin and recursive thick modeling under both criteria and averages, under six alternative preferences parametrizations: 
CASE 1: Flexible inflation targeting with weak interest rate smoothing: $\alpha=0.5, \phi=0.05$.

CASE 2: Flexible inflation targeting with interest rate smoothing: $\alpha=0.5, \phi=0.2$.

CASE 3: Flexible inflation targeting with strong interest rate smoothing: $\alpha=0.5, \phi=0.3$.

CASE 4: Strong inflation targeting with strong interest rate smoothing: $\alpha=0.7, \phi=0.3$.

CASE 5: Quasi-extreme inflation targeting with interest rate smoothing: $\alpha=0.9, \phi=0.1$.

CASE 6: Extreme inflation targeting with weak interest rate smoothing: $\alpha=1.0, \phi=0.05$.

Solving an optimal control with the loss function given by equation (17) requires expressing equations 9-16 with the corresponding algebraic transformations in state-space form. By following the Favero and Milani's (2005) representation, we have

$$
\mathbf{X}_{t+1}=\mathbf{A}_{t+1}^{j} \mathbf{X}_{t}+\mathbf{B}_{t+1}^{j} i_{t}+\boldsymbol{\varepsilon}_{t+1}
$$

where the subscript $t=1,2,3, \ldots . .42$ indicates the observations from 2001:01 to 2004:06 while the superscript $j=1,2,3, \ldots .960$ denotes the model used. The state space vector is:

$$
\begin{aligned}
\mathbf{X}_{t+1}^{\prime}= & {\left[1, \pi_{t+1}^{*}, \pi_{t+1}, \pi_{t}, \pi_{t-1}, \pi_{t-2}, \pi_{t+1}^{c}, \pi_{t}^{c}, \pi_{t-1}^{c}, \pi_{t+1}^{n c}, x_{t+1}, x_{t}, x_{t-1}, \text { ltcr }_{t}, \text { ltcr }_{t-1}, \text { ltcr }_{t-2}, u_{t+1}^{1}, x_{t+1}^{u s}, x_{t}^{u s},\right.} \\
& \left.i_{t}, i_{t-1}, i_{t-2}, u_{t+1}^{2}, w_{t+1}, \pi_{t+1}^{u s}, \pi_{t}^{u s}, i_{t+1}^{u s}, i_{t}^{u s}, \varphi_{t+1}, s_{t+1}, z_{t+1}, v_{t+1}, \text { ltcr }_{t+1}^{e}\right]
\end{aligned}
$$

The solution algorithm to the minimization problem of the loss function represented by equation (17) and subject to equations 9-16 is taken from Giordani and Söderlind (2004). The implied optimal policy rule is:

$i_{t}^{j}=\mathbf{f}_{t}^{j} \mathbf{X}_{t}$

where $\mathbf{f}_{t}^{j}$ is a $960 \times 42 \times 33$ matrix. 
Recursive thin modeling consists of estimating all possible models in every time period as new information comes along and old information gets thrown away. Out of our set of 960 estimated models, we choose the best one according to two different criteria: BIC and adjusted $\mathrm{R}^{2}$. Our estimation is based on a rolling window of fixed length, which gives us 42 different time periods. This procedure is adequate for a policy maker who obtains data in real time and learns slowly about structural breaks. Optimization is performed for every period, yet the parameters are subject to change in the future, making this a suboptimal strategy for the policy maker. ${ }^{8}$

The following table reports the inclusion percentage of every explanatory variable used for both the best output gap and core inflation specifications through time.

\begin{tabular}{|c|c|c|c|c|c|}
\hline \multicolumn{6}{|c|}{ Percentage of appearances in the best model } \\
\hline & Output gap & & & Core inflation & \\
\hline Variable & Adjusted R-squared & $\mathrm{BIC}$ & Variable & Adjusted R-squared & $\mathrm{BIC}$ \\
\hline Constant & 100.00 & 100.00 & Constant & 0.00 & 0.00 \\
\hline$x_{t-1}$ & 100.00 & 100.00 & $\pi_{t-1}^{c}$ & 100.00 & 100.00 \\
\hline$x_{t-2}$ & 16.67 & 0.00 & $\pi_{t-2}^{c} c_{-2}^{-1}$ & 40.48 & 11.90 \\
\hline$x_{t-3}$ & 76.19 & 26.19 & $\pi_{t-3}^{c-2}$ & 88.10 & 80.95 \\
\hline$x_{t-1}^{u s}$ & 100.00 & 100.00 & $x_{t}^{t-3}$ & 16.67 & 40.48 \\
\hline$x_{t-2}^{u s}$ & 4.76 & 0.00 & $x_{t-1}$ & 26.19 & 11.90 \\
\hline $\operatorname{ltcr}_{t}$ & 16.67 & 0.00 & $x_{t-2}$ & 50.00 & 38.10 \\
\hline $\operatorname{ltcr}_{t-1}$ & 33.33 & 2.38 & $x_{t-3}$ & 35.71 & 9.52 \\
\hline$r_{t-1}{ }^{t-1}$ & 90.48 & 69.05 & deinfeu $_{t}$ & 88.10 & 78.57 \\
\hline$r_{t-2}^{t-1}$ & 9.52 & 2.38 & deinfeu $_{t-1}$ & 97.62 & 45.24 \\
\hline$r_{t-3}$ & 69.05 & 30.95 & deinfeu $_{t-2}$ & 16.67 & 9.52 \\
\hline$r_{t-4}$ & 14.29 & 0.00 & deinfeu $_{t-3}$ & 52.38 & 0.00 \\
\hline
\end{tabular}

Table 1. Percentage of appearances of the explanatory variables in the best model through time.

As can be seen from Table 1, the set of variables belonging to the best specification for both the output gap and core inflation is changing through time. It is also noticeable that the first lag of the US output gap $x_{t-1}^{u s}$ is the only variable belonging to the generating set of models that is always part of the best output gap specification. ${ }^{9}$ Last but not least, the set of

\footnotetext{
${ }^{8}$ This is the case since the optimal solution is computed assuming constant parameters through time.

${ }^{9}$ The other variables exhibiting a $100 \%$ inclusion appearance in the best model are always included by the policy maker.
} 
variables being part of the best specification for both the output gap and core inflation is a function of the statistical criterion.

The fact that we use a rolling window of fixed length makes it possible to have a derived optimal policy that responds to either different coefficients when the same specification arises or different specifications when the set of inclusion variables changes. ${ }^{10}$

Recursive thick modeling involves estimating all 960 models and taking all of them into account to deal with the problem of model uncertainty at each point in time. Instead of choosing just one model, we use two averaging techniques to include the information of all models. We calculate an average of models with equal weights for each model, and a weighted average of models, in which weights vary according to the BIC or the $\overline{R^{2}}$ criterion. That is, under this last averaging technique the best models are those with larger weights.

\footnotetext{
${ }^{10}$ Optimal policies are a function of both the policy maker's preferences and the dynamic structure of the economy.
} 


\section{OPTIMALITY RESULTS VS. ACTUAL NOMINAL RATES}

The following table shows the results for the six different cases of policy preferences using the BIC criterion. EW, WA and WM stand for Equal Weights, Weighted Average and Worst Model, respectively.

\begin{tabular}{|c|c|c|c|c|c|}
\hline \multirow{2}{*}{ Loss Function } & \multirow{2}{*}{$\begin{array}{c}\text { Recursive } \\
\text { Thin }\end{array}$} & \multicolumn{2}{|c|}{ Thick } & \multirow{2}{*}{ WM } & \multirow{2}{*}{$\begin{array}{c}\text { CETES } \\
\text { 28-day rate }\end{array}$} \\
\hline & & EW & WA & & \\
\hline$L_{t}=(1-\phi)\left[\alpha\left(\pi-\pi^{*}\right)^{2}+(1-\alpha) y^{2}\right]+\phi\left(i_{t}-i_{t-1}\right)^{2}$ & $\begin{array}{c}\text { Mean } \\
\text { Std } \\
\text { MSE }\end{array}$ & $\begin{array}{l}\text { Mean } \\
\text { Std } \\
\text { MSE }\end{array}$ & $\begin{array}{c}\text { Mean } \\
\text { Std } \\
\text { MSE }\end{array}$ & $\begin{array}{c}\text { Mean } \\
\text { Std } \\
\text { MSE }\end{array}$ & $\begin{array}{c}\text { Mean } \\
\text { Std } \\
\text { MSE }\end{array}$ \\
\hline$\alpha=0.5, \phi=0.05$ & $\begin{array}{c}6.7357 \\
5.3513 \\
14.1966\end{array}$ & $\begin{array}{c}8.0175 \\
3.5489 \\
3.0136\end{array}$ & $\begin{array}{c}7.0634 \\
4.6766 \\
7.6860\end{array}$ & $\begin{array}{c}10.7419 \\
10.1122 \\
114.6773\end{array}$ & $\begin{array}{c}7.8888 \\
3.2488 \\
0\end{array}$ \\
\hline$\alpha=0.5, \phi=0.2$ & $\begin{array}{c}6.8192 \\
4.8288 \\
9.4757 \\
\end{array}$ & $\begin{array}{c}7.7772 \\
3.5651 \\
1.8207 \\
\end{array}$ & $\begin{array}{c}7.3234 \\
4.2651 \\
4.734 \\
\end{array}$ & $\begin{array}{c}9.3424 \\
5.4867 \\
29.2125 \\
\end{array}$ & $\begin{array}{c}7.8888 \\
3.2488 \\
0\end{array}$ \\
\hline$\alpha=0.5, \phi=0.3$ & $\begin{array}{c}7.031 \\
4.477 \\
6.4188 \\
\end{array}$ & $\begin{array}{c}7.804 \\
3.515 \\
1.4063 \\
\end{array}$ & $\begin{array}{c}7.5108 \\
4.0264 \\
3.2233 \\
\end{array}$ & $\begin{array}{c}8.9601 \\
4.5682 \\
17.049 \\
\end{array}$ & $\begin{array}{c}7.8888 \\
3.2488 \\
0 \\
\end{array}$ \\
\hline$\alpha=0.7, \phi=0.3$ & $\begin{array}{r}6.907 \\
4.6821 \\
8.1879 \\
\end{array}$ & $\begin{array}{c}7.8293 \\
3.5819 \\
1.6208 \\
\end{array}$ & $\begin{array}{c}7.4771 \\
4.1481 \\
3.962 \\
\end{array}$ & $\begin{array}{c}9.2785 \\
5.0435 \\
22.1157 \\
\end{array}$ & $\begin{array}{c}7.8888 \\
3.2488 \\
0 \\
\end{array}$ \\
\hline$\alpha=0.9, \phi=0.1$ & $\begin{array}{c}6.7055 \\
5.3144 \\
13.8994 \\
\end{array}$ & $\begin{array}{c}8.1377 \\
3.6837 \\
2.2104 \\
\end{array}$ & $\begin{array}{c}7.3404 \\
4.6996 \\
7.9917\end{array}$ & $\begin{array}{c}11.3727 \\
9.0304 \\
93.6\end{array}$ & $\begin{array}{c}7.8888 \\
3.2488 \\
0\end{array}$ \\
\hline$\alpha=1.0, \phi=0.05$ & $\begin{array}{c}6.7794 \\
5.6046 \\
16.6338\end{array}$ & $\begin{array}{c}8.6226 \\
3.5705 \\
3.0939\end{array}$ & $\begin{array}{c}7.4456 \\
4.8436 \\
9.2540\end{array}$ & $\begin{array}{c}12.0901 \\
12.3514 \\
171.1484\end{array}$ & $\begin{array}{c}7.8888 \\
3.2488 \\
0\end{array}$ \\
\hline
\end{tabular}

As it can be seen from the table above, under thick modeling and the policy maker's parameters $\alpha=0.5, \phi=0.3$, the average of all models with equal weights gives us the best adjustment to the actual data in terms of mean square errors. 
The following table statistically compares the difference in mean square errors among the simple average optimal policies given by some preference parameters. The MSE obtained with the loss function parameters $\alpha=0.5, \phi=0.3$ is statistically different from the ones obtained with $\alpha=0.5, \phi=0.2$ and $\alpha=0.7, \phi=0.3$ at the $5 \%$ level of significance.

\begin{tabular}{|c|c|c|}
\hline & $\alpha=0.5, \phi=0.2$ & $\alpha=0.7, \phi=0.3$ \\
\hline$\alpha=0.5, \phi=0.3$ & 0.0416 & 0.0359 \\
\hline
\end{tabular}

The numbers shown are p-values.

We do the same statistical comparison between simple and weighted averages for the revealed preference parameters. The following table shows that the MSE obtained from the simple average is statistically lower than the one given by the weighted average.

\begin{tabular}{|c|c|}
\hline $\begin{array}{c}\text { Table 4:Testing if the difference in mean square } \\
\text { errors between simple and weighted BIC averages is } \\
\text { statistically different from zero }\end{array}$ \\
\hline & $\begin{array}{c}\alpha=0.5, \phi=0.3 \\
\text { (Weighted Average) }\end{array}$ \\
\hline $\begin{array}{c}\alpha=0.5, \phi=0.3 \\
\text { (Simple Average) }\end{array}$ & 0.0005 \\
\hline
\end{tabular}

The numbers shown are p-values. 
The following table shows the results for the six different cases of policy maker's preferences using the $\overline{R^{2}}$ criterion.

\begin{tabular}{|c|c|c|c|c|c|}
\hline \multirow[t]{2}{*}{ Loss Function } & \multirow{2}{*}{\begin{tabular}{|c|} 
Recursive \\
Thin
\end{tabular}} & \multicolumn{2}{|c|}{ Thick } & \multirow{2}{*}{ WM } & \multirow{2}{*}{$\begin{array}{c}\text { CETES } \\
\text { 28-day rate }\end{array}$} \\
\hline & & EW & WA & & \\
\hline$L_{t}=(1-\phi)\left[\alpha\left(\pi-\pi^{*}\right)^{2}+(1-\alpha) y^{2}\right]+\phi\left(i_{t}-i_{t-1}\right)^{2}$ & $\begin{array}{c}\text { Mean } \\
\text { Std } \\
\text { MSE }\end{array}$ & $\begin{array}{l}\text { Mean } \\
\text { Std } \\
\text { MSE }\end{array}$ & $\begin{array}{l}\text { Mean } \\
\text { Std } \\
\text { MSE }\end{array}$ & $\begin{array}{l}\text { Mean } \\
\text { Std } \\
\text { MSE }\end{array}$ & $\begin{array}{c}\text { Mean } \\
\text { Std } \\
\text { MSE }\end{array}$ \\
\hline$\alpha=0.5, \phi=0.05$ & $\begin{array}{c}6.9038 \\
5.8589 \\
17.1229\end{array}$ & $\begin{array}{c}7.6350 \\
3.3444 \\
2.4925\end{array}$ & $\begin{array}{c}7.6198 \\
3.3797 \\
2.4974\end{array}$ & $\begin{array}{c}7.6654 \\
5.8160 \\
49.9513\end{array}$ & $\begin{array}{c}7.8888 \\
3.2488 \\
0\end{array}$ \\
\hline$\alpha=0.5, \phi=0.2$ & $\begin{array}{c}7.1764 \\
5.1124 \\
9.9594 \\
\end{array}$ & $\begin{array}{c}7.5869 \\
3.4959 \\
1.7881 \\
\end{array}$ & $\begin{array}{c}7.5787 \\
3.5187 \\
1.8203 \\
\end{array}$ & $\begin{array}{c}7.8268 \\
3.9523 \\
19.9213 \\
\end{array}$ & $\begin{array}{c}7.8888 \\
3.2488 \\
0\end{array}$ \\
\hline$\alpha=0.5, \phi=0.3$ & $\begin{array}{c}7.4377 \\
4.7119 \\
6.5692 \\
\end{array}$ & $\begin{array}{c}7.6659 \\
3.5048 \\
1.4750\end{array}$ & $\begin{array}{c}7.6619 \\
3.5213 \\
1.4969\end{array}$ & $\begin{array}{c}7.7712 \\
3.4011 \\
12.6575 \\
\end{array}$ & $\begin{array}{c}7.8888 \\
3.2488 \\
0\end{array}$ \\
\hline$\alpha=0.7, \phi=0.3$ & $\begin{array}{c}7.3566 \\
4.9195 \\
8.3429 \\
\end{array}$ & $\begin{array}{c}7.7071 \\
3.5570 \\
1.5263 \\
\end{array}$ & $\begin{array}{c}7.7015 \\
3.5747 \\
1.5572 \\
\end{array}$ & $\begin{array}{c}7.8307 \\
3.8073 \\
14.7259 \\
\end{array}$ & $\begin{array}{c}7.8888 \\
3.2488 \\
0\end{array}$ \\
\hline$\alpha=0.9, \phi=0.1$ & $\begin{array}{c}7.0699 \\
5.8289 \\
17.6568\end{array}$ & $\begin{array}{c}7.7812 \\
3.4824 \\
1.9862\end{array}$ & $\begin{array}{c}7.7699 \\
3.5120 \\
2.0282\end{array}$ & $\begin{array}{c}7.5360 \\
5.0275 \\
30.4457\end{array}$ & $\begin{array}{c}7.8888 \\
3.2488 \\
0\end{array}$ \\
\hline$\alpha=1.0, \phi=0.05$ & $\begin{array}{c}7.1845 \\
6.1656 \\
21.5236\end{array}$ & $\begin{array}{c}8.1044 \\
3.4507 \\
2.6871\end{array}$ & $\begin{array}{c}8.0925 \\
3.4844 \\
2.7216\end{array}$ & $\begin{array}{c}7.8225 \\
6.8220 \\
54.9561\end{array}$ & $\begin{array}{c}7.8888 \\
3.2488 \\
0\end{array}$ \\
\hline
\end{tabular}

It is important to mention that the simple average of optimal nominal interest rates here is different from the one obtained for the BIC criterion. This occurs because the combinations of output gap and core inflation specifications are not the same. ${ }^{11}$

\footnotetext{
${ }^{11}$ Optimal nominal interest rates are a function of combinations of output gap and core inflation specifications which vary according to the statistical criterion.
} 
The following table statistically compares the difference in mean square errors among the simple average optimal policies given by some preference parameters.

\begin{tabular}{|l|cc|}
\hline \multicolumn{3}{|c|}{$\begin{array}{c}\text { Table 6:Testing if the difference in mean square errors for simple adj. } \mathbf{R}^{2} \\
\text { averages is statistically different from zero }\end{array}$} \\
\hline & $\alpha=0.5, \phi=0.2$ & $\alpha=0.7, \phi=0.3$ \\
\hline$\alpha=0.5, \phi=0.3$ & 0.0707 & 0.3996 \\
\hline
\end{tabular}

The numbers shown are p-values.

Unlike the BIC case, the MSE obtained with the loss function parameters $\alpha=0.5, \phi=0.3$ is not statistically different from the one obtained with $\alpha=0.7, \phi=0.3$. We do the same statistical comparison between simple and weighted averages for the preference parameters $\alpha=0.5, \phi=0.3$. The following table shows that the MSE obtained from the simple average is statistically lower than the one given by the weighted average only at the $10 \%$ level of significance.

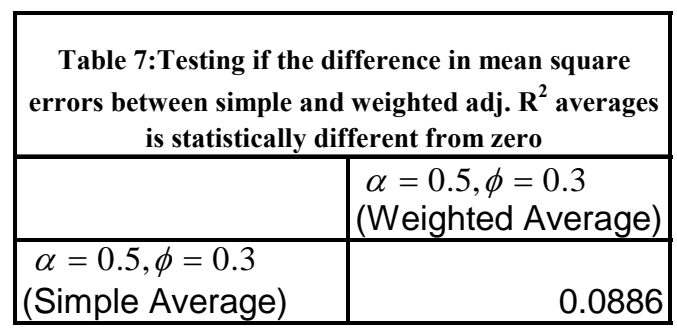

The numbers shown are p-values.

We conclude from the tables above that an equally-weighted average of 960 different models is in any case the best approximation to the interest rate setting behavior of the policy maker during this period. The results also reveal that the policy maker's preferences between stabilizing core inflation around its target and controlling output variability have been equal. The revealed preferences seem to describe a inflation targeting regime between flexible and strong with strong interest rate smoothing.

As both Table 2 and Table 5 show, when very little weight is attached to interest rate smoothing in the loss function of the policy maker (corresponding to cases 1, 5 and 6), 
the optimal monetary policy derived presents a much larger MSE than in the other cases. In particular, with preference parameters $\alpha=0.5, \phi=0.3$ and $\alpha=0.7, \phi=0.3$ the optimal interest rates obtained under recursive thin modeling and recursive thick modeling have means and standard deviations closer to those of the actual series.

Last but not least, in following the spirit in Capistrán and Timmermann (2006) to improve the tracking job of historical nominal rates, we use an affine transformation of the simple averages. We find no statistical difference between the mean square errors given by the affine transformation of the simple averages and the simple averages themselves.

\section{CONCLUSIONS}

Just like it is done in Favero and Milani (2005), thick modeling is implemented here to deal with parameter instability and model uncertainty. We find that those problems are relevant to determining the evolution of the state variables on which monetary policy exerts some influence. Recursive modeling is complemented with thick modeling in every period in order to mimic the behavior of an optimal policy maker who takes decisions relying only on available data up to that point and bearing in mind model uncertainty. The policy maker takes into account only a very specific type of model uncertainty by making all the possible combinations from a base set of $k$ regressors. We find the optimal policy rules implied by each model and take their simple or weighted average according to some statistical criterion. We find that the implied optimal nominal interest rates for any given period substantially vary across specifications. Furthermore, we compare the optimal policy implied by the best model in each period (recursive thin modeling) to simple and weighted averages of all the optimal nominal rates (recursive thick modeling) in terms of tracking the historical nominal interest rate in Mexico from January 2001 to June 2004. We are able to do a better tracking job of the actual nominal interest rates when using averages. These results argue in favor of making it necessary to take model uncertainty into account when setting monetary policy. 
By statistically comparing the MSEs obtained from the average optimal policies given by different preference parameters, we are able to reveal only a range in which the revealed preference parameters could be. We do the same statistical comparison between simple and weighted averages only for the preference parameters $\alpha=0.5, \phi=0.3$. We find that simple averages work better than weighted averages. The results also show both reductions in bias and standard deviation in tracking the actual nominal interest rates when using either simple or weighted averages of optimal nominal interest rates.

The results also indicate that the set of variables belonging to the best specification for both the output gap and core inflation is changing through time. Last but not least, in following the spirit in Capistrán and Timmermann (2006) to improve the tracking job of historical nominal rates, we use an affine transformation of the simple averages obtained from preference parameters $\alpha=0.5, \phi=0.3$. We find no statistical difference between the mean square errors given by the affine transformation of the simple averages and the simple averages themselves.

\section{REFERENCES}

Ball, L. (1999). Policy Rules for Open Economies. In J. Taylor (ed.), Monetary Policy Rules, The University of Chicago Press.

Bossaerts, P. and Hillion, P. (1999). Implementing Statistical Criteria to Select Return Forecasting Models: What Do We Learn? Review of Financial Studies, 12, 405-428.

Brainard, W. (1967). Uncertainty and the Effectiveness of Policy. American Economic Review, Papers and Proceedings 57, 411-425.

Capistrán, C. and A. Timmermann. (2006). Affine Transformation of Mean Forecasts: A Refinement of Equal-Weighted Forecast Combinations, Mimeo, Banco de México and UCSD.

Contreras M., G. and García S., P. (2002). Estimación de Brecha y Tendencia para la Economía Chilena. Revista de Economía Chilena, 5(2), 37-55.

Dell'Aquila, R. and Ronchetti, E. (2004). Stock and Bond Return Predictability: The Discrimination Power of Model Selection Criteria. Université de Genève Working 
Paper No. 2004.05.

Eichenbaum, M. and Evans, C. (1995). Some Empirical Evidence on the Effects of Monetary Policy Shocks on Exchange Rates. Quarterly Journal of Economics, 110, 975-1009.

Engert, W. and Selody, J. (1998). Uncertainty and Multiple Paradigms of the Transmission Mechanism. Bank of Canada Working Paper No. 98-7.

Favero, C. A. and Milani, F. (2005). Parameter Instability, Model Uncertainty and the Choice of Monetary Policy. B.E. Journals in Macroeconomics: Topics in Macroeconomics, 5, 1-31.

Giordani, P. and Söderlind, P. (2004). Solution of macro-models with Hansen-Sargent robust policies: some extensions. Journal of Economic Dynamics and Control, 28, 2367-2397.

Gourinchas, P. and Tornell, A. (1996). Exchange Rate Dynamics and Learning. NBER, Working Paper No. 5530.

Granger, C.W.J. and Jeon, Y. (2004). Thick modeling. Economic Modelling, 21, 191-385.

Hansen, L. and Sargent, T. (2003). Robust Control and Model Uncertainty in Macroeconomics. Manuscript, www.stanford.edu/ sargent

Honda, Y. (1982). On Tests of Equality Between Sets of Coefficients in Two Linear Regressions When Disturbance Variances Are Unequal, The Manchester School, 49, 116- 125.

Jenkins, P. and Longworth, D. (2002). Monetary Policy and Uncertainty. Bank of Canada Review (Summer): 3-10.

Milani, F. (2003). Monetary Policy with a Wider Information Set: a Bayesian Model Averaging Approach. Mimeo, Princeton University.

Onatski, A. and Stock, J.H. (2002). Robust monetary policy under model uncertainty in a small model of the U.S. economy. Macroeconomic Dynamics, 6, 85-110.

Pesaran, M.H. and Timmermann, A. (1995). Predictability of Stock Returns: Robustness and Economic Significance.

Roldán-Peña, Jéssica (2005). Un Análisis de la Política Monetaria en México bajo el Esquema de Objetivos de Inflación. Tesis de Licenciatura en Economía, ITAM.

Rudebusch, G.D., and Svensson, L.E.O. (1999). Policy Rules for Inflation Targeting. In J. 
Taylor (ed.), Monetary Policy Rules, The University of Chicago Press.

Söderström, U. (2002). Monetary Policy with Uncertain Parameters. Scandinavian Journal of Economics, 104(1), 125-145.

Watt, P. A., (1979). Tests of Equality Between Sets of Coefficients in Two Linear

Regressions When Disturbance Variances Are Unequal: Some Small Sample Properties, The Manchester School, 47, 391-396. 